\title{
Telehealth for Pediatric Cardiology Practitioners in the Time of COVID-19
}

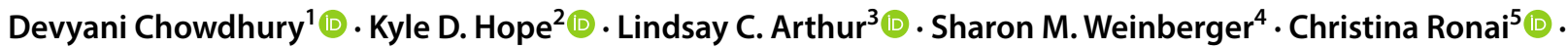 \\ Jonathan N. Johnson ${ }^{6}$ (i) . Christopher S. Snyder ${ }^{7}$
}

Received: 17 May 2020 / Accepted: 3 July 2020 / Published online: 12 July 2020

○) Springer Science+Business Media, LLC, part of Springer Nature 2020

\begin{abstract}
Due to the COVID-19 pandemic, there has been an increased interest in telehealth as a means of providing care for children by a pediatric cardiologist. In this article, we provide an overview of telehealth utilization as an extension of current pediatric cardiology practices and provide some insight into the rapid shift made to quickly implement these telehealth services into our everyday practices due to COVID-19 personal distancing requirements. Our panel will review helpful tips into the selection of appropriate patient populations and specific cardiac diagnoses for telehealth that put patient and family safety concerns first. Numerous practical considerations in conducting a telehealth visit must be taken into account to ensure optimal use of this technology. The use of adapted staffing and billing models and expanded means of remote monitoring will aid in the incorporation of telehealth into more widespread pediatric cardiology practice. Future directions to sustain this platform include the refinement of telehealth care strategies, defining best practices, including telehealth in the fellowship curriculum and continuing advocacy for technology.
\end{abstract}

Keywords Telehealth $\cdot$ Telemedicine $\cdot$ Remote monitoring $\cdot$ Pediatric cardiology

\section{Introduction}

Devyani Chowdhury and Kyle D. Hope have contributed equally to this work.

Devyani Chowdhury

dchowdhury@ cardiologylancaster.com

1 Cardiology Care for Children, 1834 Oregon Pike, Ste 20, Lancaster, PA 17601, USA

2 Lille Frank Abercrombie Section of Cardiology, Department of Pediatrics, Texas Children's Hospital, Baylor College of Medicine, Houston, TX, USA

3 Division of Pediatric Cardiology, Department of Pediatrics, University of Arkansas for Medical Sciences, Little Rock, AR, USA

4 Nemours Cardiac Center, Nemours AI DuPont Children's Hospital, Wilmington, DE, USA

5 Division of Pediatric Cardiology, Department of Pediatrics, Oregon Health \& Sciences University, Portland, OR, USA

6 Division of Pediatric Cardiology, Department of Pediatric and Adolescent Medicine, Mayo Clinic Children's Center, Rochester, MN, USA

7 The Congenital Heart Collaborative, Case Western Reserve University School of Medicine, Cleveland, OH, USA
In late December 2019, a series of patients with pneumonia were reported in Wuhan, China [1]. Further investigation by the World Health Organization identified the cause of the pneumonia as a novel coronavirus belonging to the same family responsible for previous outbreaks such as severe acute respiratory syndrome (SARS) and Middle East Respiratory Syndrome (MERS). By mid-January, the disease had spread throughout the world, eventually meeting the criteria established by the WHO as a global pandemic (COVID-19) [2].

Since its onset, COVID-19 has challenged providers to develop safe and effective means to provide appropriate, time sensitive, and lifesaving care to patients. As a direct result of the pandemic, there has been a newfound interest in providing telehealth, also called telemedicine, due to the need to balance personal distancing precautions with patient care. We believe this new increase in use of telehealth in pediatric cardiology due to the COVID-19 pandemic will have a lasting impact on our daily practice.

Despite its longstanding history, telemedicine has not been utilized as a primary means of providing pediatric 
cardiac care in the majority of healthcare facilities. With the seemingly overnight call for transformation of patient interaction due to COVID-19, the advantages and disadvantages of telemedicine are being closely examined. The role of telehealth within pediatric cardiology is particularly valuable given the need for prompt diagnosis and reliance on a multitude of factors including history, physical examination and advanced testing (EKG, chest X-ray, and echocardiography) to arrive at the correct diagnosis, which may be lifethreatening. Specific areas explored in this paper include our attempt to identify appropriate patient populations, evaluation of those specific diagnoses best suited for telehealth, the practical implications of performing a telehealth visit, use of remote monitoring, staffing needs and resource utilization, billing, incorporation of telehealth into current practice, and the role for pediatric cardiology fellows in telehealth.

\section{Background}

While the current COVID-19 pandemic has generated urgency in the adaptation of patient care within the confines of personal distancing, significant contributions to the practice of telemedicine in the field of pediatric cardiology have previously been reported. Telemedicine is defined as the "specific application of technology to conduct clinical medicine at a distance and establishment of a connection between physicians and patients in a multitude of settings" [3]. This includes its value in fetal echocardiography and fetal cardiac monitoring, neonatal consultation for the sick newborn with suspected congenial heart disease, the care of pediatric patients presenting for follow-up care or to the local emergency department with acquired heart disease, and providing expertise in the management of the adult congenital patient [4-9]. Multiple publications have detailed the ability of telehealth to extend subspecialty availability and expertise to rural or community practices without an on-site pediatric cardiologist [10-13]. A study of telehealth in a Portuguese pediatric cardiology practice noted improved access to patients living in rural areas and the ability of global outreach to cardiologists working in low and middleincome countries [11].

Furthermore, a review of current technologies vital to the day-to-day operation of a robust telecardiology service exists including the use of tele-echocardiography, tele-auscultation, and remote rhythm monitoring [14-26]. Reports offering guidance in creating a high-quality pediatric telemedicine program have been the subject of numerous works with particular attention to details of initial planning, options regarding various clinical care models, and proposed metrics for ongoing quality assessment [3, 27-30]. This extensive body of literature led to the culmination of a scientific statement by the American Heart Association in 2017 addressing the use of telemedicine in pediatric cardiology [3].

Outcome data regarding telemedicine within the field of pediatric cardiology are promising. Several studies have shown improvement in providing high quality of care to a greater number of patients and improvement in prompt and accurate diagnoses with its utilization [6, 31-36]. Furthermore, telemedicine has been shown to have significant cost savings and financial gain to the healthcare system as a whole $[37,38]$. In addition to its use in clinical medicine, the application of remote education in the form of tele-education of providers and trainees is well established [39-41].

While many aspects of telemedicine have had major success, it is not without its own set of obstacles. Barriers to its use include lack of standardization of telemedicine components, complex legal issues and licensure requirements, insurance reimbursements, and provider and patient acceptance [27]. While there was a rapid acceptance of this technology by government and insurance entities to allow for providers to continue to provide care for their patients, the recommendations and regulations continue to evolve.

\section{Population}

In general, patients who might benefit from such a transition to telehealth include those with adequate resources to complete the visit including a computer or phone-based system, a stable connection (internet, phone line), the ability to dedicate time to the visit, and the ability to afford the cost of data required for video calls. Provider requirements for incorporating telehealth include adequate institutional support such as a HIPAA-compliant platform, tech support, equipment, training, care maps and clinical pathways that are consistent across the program, scheduling support, and outpatient templates that accommodate telehealth.

Telehealth may also represent a paradigm shift in reaching patients with barriers to in-person appointments. Decreased travel costs and savings of travel time may help those living distant from their pediatric cardiologist or with lack of transportation [11]. Telehealth may also allow a glimpse into the home environment of patients, providing insights into their lives that may never have been known otherwise [42]. Telehealth may help decrease no-show rates in clinic, helping pediatric cardiology teams to provide care to a greater number of patients each day. Finally, telehealth may also help facilitate greater accessibility to subspecialty pediatric cardiovascular care at a population level with increased patient outreach and ease of access. With the back log of patient visits, telehealth may facilitate decreased wait times for appointments, and allow for a more efficient triage system for in-office visits and tests. 
In spite of all these advantages, telehealth may not be appropriate for all pediatric cardiology patients. For instance, telehealth may not be best suited in emergent situations where rapid notification of emergency medical providers is indicated for patient safety (with the rare exceptions where the telehealth care model is designed for assisting local care providers in the acute stabilization of a patient). Telehealth represents a knowledge-rich but resource-poor environment: while a specialist with knowledge is present, there are often few interventions that can be done remotely until patient is physically brought to a medical facility. Telehealth may aid in triaging providers by determining the best disposition for patient evaluation if a patient is calling from home with concerns. Video assessment may help guide whether a patient can be seen in the outpatient clinic in several hours or days, or whether presentation to the nearest medical center or activating emergency medical services is more appropriate.

Telemedicine may not be appropriate for a population requiring objective data to render a complete evaluation. Seeing patients without means of assessing vital signs such as heart rate, oxygen saturation, or weight trends at home may not be the best alternative in newborns or any patient that is critically ill. Physical examination signs such as a subtle change in murmur, pulse quality, or volume status may also be poorly conveyed by video or by an examination performed by a non-medical family member over telehealth.

\section{Performing Telehealth}

Prior to beginning any telehealth encounters, it is important that the telehealth team be equipped to deliver high-quality care. A recent AAP webinar on telehealth may serve as a useful reference [43]. Many institutions were able to expand basic telehealth infrastructure to accommodate the surge in need during the COVID-19 pandemic and may have different policies and procedures that must be followed. Before arranging the telehealth encounter, consent from the patient or parent must be obtained and on file. This can be either obtained verbally or in writing. While certain HIPAA regulations regarding telehealth were relaxed during the initial phase of the COVID-19 crisis, a HIPAA-compliant telehealth modality is preferred and will be needed going forward as regulations resume post-pandemic. Non-HIPAAcompliant platforms with direct communication to the patient such as Facetime ${ }^{\mathrm{TM}}$ (Apple, Cupertino, CA), Duo ${ }^{\mathrm{TM}}$ (Google, Mountain View, CA), WhatsApp ${ }^{\mathrm{TM}}$ (Facebook, Inc., Menlo Park, CA), and Google Hangouts ${ }^{\mathrm{TM}}$ (Google, Mountain View, CA) are all permissible at the present time. Several HIPAA-compliant platforms are also commercially available for office-based practices. Larger institutions may have the infrastructure to incorporate video telehealth via the electronic medical record (EMR), allowing for easier access to patient data during the encounter, patient scheduling, billing, and insurance information. Some platforms allow for group appointments which may allow for multiple members to be present for the appointment. Several features for translation are also available with these platforms.

Most aspects of the in-person encounter can be readily adapted to a telehealth encounter, as described in the following sections. A helpful list of Telehealth Do's and Don'ts are found in Table 1.

\section{Assessing Suitability of Telehealth}

While it is important for cardiologists to protect themselves, the healthcare team, patients, and families from unnecessary exposure, not all patients are suitable for initial visit via telemedicine. There are certain circumstances in which the patient's initial encounter with the cardiac team should be a face-to-face visit, as teleconsultation in these patients may prolong time to diagnosis of a potentially life-threatening illness. In these cases, patients should be seen in person for a complete evaluation by a pediatric cardiologist. Broad categories of younger patients that may be less suitable for an initial evaluation by telehealth include infants with a murmur or cyanosis, infants or toddlers with failure to thrive, and a post-natal evaluation after pre-natal suspicion for congenital heart disease. Older patients with concerns for exertional chest pain or syncope, cardiomegaly on chest imaging, an abnormal EKG with symptoms, or a family history of sudden cardiac death in a first degree relative may all be less suitable for an initial telehealth visit. When tests such as an EKG or echocardiogram are essential for assessment, an office visit would be preferred. Other circumstances such as needing clearance for a non-deferrable surgery, time-dependent diagnoses such as Kawasaki follow-up, or an evaluation prior to chemotherapy should also be seen in person. In all situations, the provider should use their clinical judgment to determine if in-person or telehealth visits are best for the individual patient scenario.

Initial consultation via telemedicine may include chief complaints such as palpitations, chest pain at rest, dizziness/ syncope, dyslipidemia (if a lipid profile is available), hypertension, patients with an abnormal EKG, and patients with a family history of genetic disorders. Based on the initial consultation, more information will be available and further testing may be ordered. Additionally, an initial telehealth consult may uncover "red flag" symptoms that would prompt a more urgent in-person visit. Once personal distancing restrictions have been lifted, the non-urgent patient may then follow-up in person for a complete physical examination and further testing as per standard of care. 
Table 1 Do's and don'ts of telehealth in pediatric cardiology

The do's and don'ts of telehealth in pediatric cardiology

Do's

Do the background work (i.e., make sure you have the appropriate billing codes, clearance from insurers, institutional approval, HIPAA compliance)

Do establish the workflow for the telehealth visit including EMR documentation

Do be transparent with patients and families: establish expectations of length of visits, potential charges and reimbursement, etc

Do utilize ancillary staff to help set up appointments, "virtually" room the patients, record vitals, document medications, etc

Do make the effort to maximize the patient experience: for any telehealth visit, minimize background noise, wear professional attire, use diagrams or videos if able, have an uncluttered background

Do establish a clear follow-up plan, including the need for future faceto-face visits or testing

Do utilize the full array of options to keep patients home: consider returning heart rhythm monitors by mail, using smaller community labs or home care nursing-facilitated blood draws
Don'ts

Don't complain to the patient about having to use telehealth! They may also be frustrated in learning a new process

Don't try to make every visit telehealth—pick what will work best within your practice and your patient population. Having telehealth capabilities does not mean that every visit has to be telehealth

Don't start a video or phone call without preparing for the visit just as you would for a face-to-face encounter

Don't get distracted during the telehealth visit. Keep your cell phone and email closed and out of sight, conduct visits from an area where you are not likely to be interrupted or disturbed

prior vital signs and (potentially) cardio-diagnostic testing can be reviewed. If the family and physician are not fluent in the same languages, it is imperative that third-party medical translator services aid in communication during these interactions. Symptom assessment should include questions regarding breathlessness, dyspnea, loss of appetite and changes in activity level, with special attention to trends over time. One example of a symptom suited for telehealth is assessment of "bendopnea," in which tachypnea is elicited when the patient bends forward at the waist while sitting. This can be assessed easily by telehealth and can provide evidence of heart failure severity [44].

\section{Physical Exam}

Acquisition of vital signs in the home setting can be challenging in the pediatric population. Unlike with adults, an appropriate size blood pressure cuff for babies and young children is rarely available in the average home. However, teenage patients may be able to use adult-sized home blood pressure cuffs and orthostatic vital signs (if relevant) can be obtained with proper guidance. Despite the inability to auscultate the heart and lungs, or to palpate the liver edge or pulses, a reasonable amount of information can be gathered from home teleconsultation. The general physical appearance and psychiatric state can be easily observed during history-taking. The physician can inspect for cyanosis, dysmorphisms of the face and ears, and even dentition. In babies and younger children labored breathing, pectus deformity, umbilical hernia, surgical scars and ostomy tube sites can 
be assessed. A reasonable examination of extremities can be done, observing for deformities, features of connective tissue disease, and clubbing. An assessment of the patient's skin to look for cyanosis, hemangiomas, acanthosis nigricans, stretch marks, or stigmata of other systemic or genetic diseases is possible. In patients who are developmentally able, assessment of gait can be performed.

\section{Assessment}

The summary of the assessment should always include the limitations of the examination and therefore of the overall assessment. This must be stated clearly to the parent to prevent misunderstanding regarding the utility of the interaction. Physicians can formulate their impressions based on available information and may recommend remote testing. Physicians can also review the EMR for other encounters. Often, a recent set of vitals can be located. In addition, the results of blood work, EKGs, and chest X-rays performed in the past can also be assessed. All of these data feed into a comprehensive assessment and decision-making plan for the patient.

The application of teleconsultation in pediatric cardiology is a phenomenon borne of necessity, with limited prior data. There are benefits of this technology in a time of personal distancing, including the ability to establish relationships with families in remote locations, or families in whom finances or transportation would have otherwise precluded an outpatient visit $[45,46]$. For situations in which parents are no longer living together, both parents can be present at an appointment via teleconference, easing communication barriers. The elimination of travel time to and from appointments minimizes disruption to school and workdays [47]. Surveys of families who have engaged with their physicians in this way demonstrated a high degree of parent satisfaction with this type of interaction [48-53]. Most importantly, use of telemedicine has been shown to improve outcomes in single ventricle patients [54-56], as well as adults with heart failure [57, 58], hypertension [59, 60], and dyslipidemia [61]. Expanding the use of telehealth may help cardiologists to capitalize on these benefits and perhaps establish a precedent for future interactions.

\section{Additional Testing}

The availability of remote cardiac testing allows for the acquisition of EKGs at a local pediatrician's clinic or urgent care office, and ambulatory rhythm monitors can be delivered to the patient's home. Whenever possible, physicians should abide by appropriate use criteria when ordering diagnostic testing, as certain diagnostic tests require prolonged contact between patient and the medical team, increasing the risk of exposure [62]. However, a strategy of allowing a patient to present for testing such as an EKG or echocardiogram prior to a planned telehealth encounter may convey several advantages for both the patient and provider. A patient's overall time spent in a medical environment would be less when compared to an all-inclusive in-person clinic visit. Patients would also come into contact with fewer medical staff during the course of their encounter. Finally, the availability of testing results to reference and review at the time of the telehealth encounter would be of great benefit to both the patient and the telehealth provider, would add further value to the encounter, and would certainly aid in medical decision-making.

\section{Follow-Up}

If an initial telehealth visit is performed for a new patient, then an in-person examination can be performed whenever permissible to meet the standard of care for an initial visit. In patients in whom structural or acquired heart disease is suspected, a face-to-face visit with appropriate diagnostic imaging should be arranged so that a physical exam may be performed and definitive diagnosis achieved. In established patients with known heart disease, such as a NICU or newborn nursery follow-up, echo-only appointments may be arranged to minimize contact with clinic staff while obtaining needed information.

Patients in whom a physical exam is typically normal may continue to follow-up as needed via telehealth until personal distancing restrictions are lifted. This strategy is of optimal utility in children with dyslipidemia, in whom laboratory studies can be obtained at a local facility and transmitted to the ordering physician. Patients with high blood pressure, vasovagal presyncope or syncope, and postural orthostatic tachycardia syndrome may also be suited to this type of interaction. It is, however, important to recognize that after a finite number of telehealth visits, irrespective of their diagnosis, patients should have an in-person assessment with a cardiologist. Patients presenting for second opinions, especially from distant locations, may be especially suited for telehealth as robust data from the parent center are typically available for review.

\section{Disorders of Cardiac Rhythm and Conduction}

Cardiac arrhythmias are a common cause of morbidity and the Task Force on Children and Youth estimates that up to 30,000 children will have a newly diagnosed cardiac arrhythmia or conduction abnormality yearly [63]. Advancements in remote real-time monitoring make electrophysiology particularly well suited for telemedicine. The establishment of digital electrocardiography has allowed for consultation and detection of those diagnoses with abnormalities on resting electrocardiograms 
such as Brugada or prolonged QT syndromes. Additionally, remote viewing of rhythms on cardiac monitoring in the in-patient or emergency department setting allows for real-time interpretation and treatment initiation with telecardiology supervision [64]. The use of telemedicine in a hospital setting, many technological capabilities have enabled pediatric cardiologists to provide care outside of the traditional face-to-face in-office setting. Since pediatric arrhythmias are predominantly paroxysmal in nature, their detection relies on capturing the event. This is most often done through the use of 24-h ambulatory monitors (Holter monitors), external event or telemetry monitors, or implantable loop recorders. Holter monitor and rhythm monitors can be placed in the office or mailed to patient homes $[23,25]$. Patients who have implantable pacemakers and cardioverter-defibrillators have the capacity to record and transmit data remotely through a landline or cellular phone allowing for identification of problems and treatment without the need for clinic visits [22, 24, 26, 65-67]. These remote monitoring capabilities additionally allow the care team to check the functionality of the device, battery, and leads in addition to the ability to review intra-cardiac electrograms.

In addition to the standard devices used in outpatient arrhythmia monitoring, there is a growing market of directto-consumer devices that enable families to monitor their children and provide sharable information for their physician. The data obtained from these devices have several limitations which make their application in clinical decisionmaking a challenge.

\section{Fetal Cardiology}

Fetal cardiology has become subjected to a strict triage process during the pandemic, as performance of a fetal echocardiogram requires significant contact between the mother and the members of the fetal cardiac team. The fetal echocardiogram cannot be suitably performed via telehealth as imaging is a significant component of the visit. However, telehealth can be used to triage the reasons and timing of the study. Both the interaction with the sonographer and the cardiologist are lengthy and increase exposure risks. Therefore, the decision to perform a fetal echocardiogram must weigh the risk of exposure against the utility of the interaction. Recent statements by the American Society of Echocardiography have strongly discouraged performance of non-urgent imaging [62]. These referrals have been stratified into low-, medium-, and high-acuity categories. Performance of fetal echocardiography should therefore be limited to those in whom there is a time-sensitive component, cases that pose a risk to fetal viability, or cases in which medical or other interventions may be indicated [68].

\section{Existing Home Monitoring in High-Risk Pediatric Cardiology Populations}

The existing use of telehealth and remote monitoring for specific diagnoses and conditions may help guide a broader incorporation of telehealth practices to other pediatric cardiology populations.

\section{Single Ventricle Heart Disease}

Technology has already been leveraged to help pediatric cardiologists monitor the single ventricle population during the critical interstage period [69]. While the interstage period is defined as the time between the Norwood surgery and Glenn surgery, many care teams have expanded this monitoring to all single ventricle infants [including those with ductal stents, pulmonary artery (PA) bands, and Blalock-Thomas-Taussig (BTT) shunts without arch augmentation]. Infants are sent home with a scale and pulse oximeter in order to monitor their weight gain and oxygen saturations and families are well educated about "red flags" which prompt a phone call to their care team if certain thresholds are reached. The use of electronic tablets or cell phone applications by many institutions allows families to input daily weights and oxygen saturations into devices so that their cardiology teams can monitor them remotely $[70,71]$. The equipment is supplied by the care team to allow remote, automated transmission of data. While there is some ability to bill for these devices and remote monitoring, most of the funding is covered by the care team or grants. These devices are HIPAA-compliant and can be used to conduct virtual visits. This program is being extended at this time to other heart failure patients (like ventricular septal defect or AV canal defect) who require closer monitoring. Patients with Tetralogy of Fallot or other shunt-dependent patients can also be evaluated using these types of platforms.

\section{Ventricular Assist Devices}

Children with ventricular assist devices (VADs) are able to be discharged after device placement, with $59 \%$ of patients with intracorporeal continuous flow devices able to leave the hospital according to the most recent Pedimacs registry data [72]. Adapting VAD outpatient visits to a telehealth setting is feasible and can enable similar surveillance as in-person visits. While patients should be seen in person for their first several visits after hospital discharge given the need for close monitoring of device complications and continued education in the immediate post-implant period, telehealth should be considered an option for those patients requiring routine outpatient checks while stable on long-term support. 
Prior to the telehealth visit, patients can upload images of their driveline site and dressing via phone camera or apps linked to the electronic medical record, images of their VAD controller with values for flow and power visible, VAD log file detailing long-term trends in device flows and power, and images of any bruising, swelling, or changes of concern to the patient or their family. Alarm logs should also be submitted and the circumstances surrounding each alarm carefully clarified; alarms associated with symptoms require in-person evaluation. These data should be reviewed for concerning changes or trends. Submission of these data to the VAD team on regular intervals between telehealth visits can further aid in continued outpatient surveillance. Use of outpatient laboratory visits or home-based draws can help provide continued laboratory surveillance while limiting patients' exposure to a hospital environment. Home international normalized ratio (INR) monitors are available and can help monitor anticoagulation. Medical emergencies can be life-threatening without prompt intervention in patients supported by VADs, and telehealth should never be considered a substitute for in-person evaluation in emergent situations.

\section{Staffing and Resource Utilization}

Due to the COVID-19 pandemic, the responsibilities for many aspects of care have shifted with the rapid utilization of telehealth, placing an increased workload on the provider performing the visit. Rooming, vitals, completing EMR history, medication reconciliation, placing orders and communicating the follow-up plan, and note composition now are all largely completed by the provider. In some situations, the provider may even need to collect the payments. While some programs may utilize this as a means of consolidating their staff to only a few essential persons, others may re-deploy office-based staff to assist with these virtual tasks. Other staffing and resource utilization changes may arise from changes in patient volumes secondary to the COVID-19 associated pandemic and the widespread stay at home orders. Decreased in-patient clinic visits have led to a decreased use of in-office diagnostic testing such as echocardiograms and EKGs. Similarly, there may be a decrease in the need for echocardiogram and MRI readers during the pandemic as these diagnostic modalities are utilized less frequently as non-emergent testing and visits are deferred.

It will be a challenge for programs that measure physician productivity with traditional measures such as the revenue value unit (RVU), and different metrics must be considered to assess physician contributions to patient care in the telehealth era. Care teams may have to work longer hours once personal distancing restrictions are lifted to make up for the back log of patient visits deferred during the pandemic. In the process of re-opening after the pandemic, it may become particularly important to incorporate telehealth in order to decrease patient wait times and increase access to care.

\section{Billing and Coding}

As the pandemic unfolded, the Centers for Medicare and Medicaid Services (CMS) rapidly approved specific billing codes for telehealth. These codes were made at par with regular office visit codes [73] and provide significant financial support to practices and institutions affected by a loss of in-person patient volume. This also provides a financial incentive for practices and institutions to adopt and expand their telehealth offerings. A list of billing codes useful for telehealth encounters can be found in Table 2.

\section{Fellowship Training in Telehealth}

The most recent SPCTPD/ACC/AAP/AHA training guidelines for pediatric cardiology fellowship programs released in 2015 [74] do not address the incorporation of telehealth into pediatric cardiology education. A recent AHA Scientific Statement on telemedicine in pediatric cardiology [3] briefly addressed the need for additional training, noting that even cardiology fellowship programs associated with centers possessing existing telehealth capabilities rarely have requirements in telehealth competency as part of their fellows' curriculum. The AHA statement further notes that few pediatric cardiology fellows are graduating with the skills needed to incorporate telehealth into their practice. In response to the COVID-19 crisis, the Accreditation Council for Graduate Medical Education (ACGME) has released guidance related to fellows and their involvement in telehealth, immediately authorizing fellows to participate in telehealth with appropriate supervision to care for patients during the pandemic [75].

Given the fact that many staff and fellow pediatric cardiologists lack formal telehealth training, this pandemic represents an opportunity for learning together. Numerous guides and best practices have been published by the American Academy of Pediatrics [76], the American College of Cardiology [77], and other medical organizations to address the groundswell of interest and rapid incorporation of telehealth; some of these resources are geared towards trainees [78-80]. This may possibly lead to adding telehealth training to fellowship curricula and encouraging industry to develop platforms that aid in allowing multiple providers in a telehealth visit so that learners of all levels may continue to participate in patient care.

As staff cardiologists incorporate more telehealth into their practices, fellows similarly should be incorporated into telehealth workflow [80]. Many innovative strategies have 
Table 2 Billing codes in telehealth encounters

\begin{tabular}{|c|c|c|}
\hline Type & Codes & Modifier \\
\hline \multicolumn{3}{|l|}{ Tele/video calls } \\
\hline - Time based & 99212-99215 (Follow-up) & $\begin{array}{l}\text { Modifiers GT or } 95 \text { (billing } \\
\text { company to add a loca- } \\
\text { tion for the service, } 02 \\
\text { modifier) }\end{array}$ \\
\hline - Face-to-face time & $\begin{array}{l}\text { 99241-99245 (New consult) } \\
99201-99205 \text { (Not seen for }>3 \text { years) }\end{array}$ & \\
\hline \multicolumn{3}{|l|}{ Telephone calls } \\
\hline \multirow[t]{3}{*}{ - Time based } & 99441: 0-10 min & $\begin{array}{l}\text { Modifiers GT or } 95 \text { (billing } \\
\text { company to add a loca- } \\
\text { tion for the service, } 02 \\
\text { modifier) }\end{array}$ \\
\hline & 99442: 10-20 min & \\
\hline & 99443: greater than $20 \mathrm{~min}$ & \\
\hline $\begin{array}{l}\text { Inter-professional consultation: consulting physician for time spent } \\
\text { on electronic consultation between generalist and specialist }\end{array}$ & $99446-99449$ & \\
\hline
\end{tabular}

been developed and successfully deployed to continue fellowship training and education during the COVID-19 crisis $[81,82]$ including regular webinars that are focused on the congenital cardiologist [83]; telehealth similarly represents an opportunity to continue to provide education in patient care in a different format during this trying period. In a time where personal distancing and separation are keeping individuals apart, including faculty from fellows, telehealth is a means to come together for patient care in a safe manner.

\section{Future Directions}

The expanded role of telehealth brought about by the COVID-19 pandemic is unlikely to disappear after this pandemic has abated. For telehealth to be sustainable, care maps and strategies for optimal utilization of this tool in the care of pediatric patients with heart disease must be developed. Pediatric cardiologists will need to work with advocacy groups and legislators to ensure that adequate reimbursement for telehealth encounters takes place, which will allow for the continued use of this technology. Exploring means of providing patients with access to remote monitoring equipment and equipment to measure objective vital sign data will additionally help lead to higher quality telehealth encounters with improved patient care. For example, many families do not possess the necessary medical equipment for obtaining reliable vital signs at home. Pre-packaged kits containing equipment such as finger pulse oximeter and an age-appropriate blood pressure cuff and sphygmomanometer could be easily generated and mailed to families to aid in the collection of accurate vital signs during a telehealth encounter. This may represent an easily addressed means to increase the quality and safety of a home telehealth encounter. This intervention would require support from payors for reimbursement and from the biomedical industry for providing age-appropriate pediatric equipment.

\section{Summary}

Telehealth will continue to be incorporated into pediatric cardiac clinical practice after the acute phase of the COVID-19 pandemic has passed. We will learn as a field as to which conditions and diagnosis are best suited for telehealth, though telehealth visits will never replace in-person visits entirely. Patients with other barriers to in-person care may see an increased access to care as a result of telehealth expansion. Telehealth also holds the promise of decreasing the no-show rate and the patient wait times for appointments.

This pandemic lends itself to collaborative learning, with pediatric cardiology as no exception. There is potential to gather evidence about the optimal frequency of patient follow-up visits, the usefulness of appropriate use criteria for echocardiography, and the best utilization of emerging telehealth technology. It may steer our field towards a more appropriate resource utilization for pediatric cardiology care. The COVID-19 pandemic may serve as a catalyst in improving resource utilization, improving quality of care, and advancing pediatric cardiology practices to improve patient care outcomes.

Authors Contributions Conceptualization: DC, CSS; Writing-original draft preparation: all authors; Writing—review and editing: $\mathrm{DC}, \mathrm{KDH}$; Supervision: DC, CSS. 
Funding None.

Data Availability Not applicable.Consent to Participate Not applicable.

Consent for Publication Not applicable.

Code Availability Not applicable.

\section{Compliance with Ethical Standards}

Conflicts of interest The authors declare that they have no conflict of interest.

Ethical Approval Not applicable.

\section{References}

1. World Health Organization (2020) Novel coronavirus (2019nCoV) situation reports: 1. https://bit.ly/2UVXVsD. Accessed 19 Jan 2020

2. Centers for Disease Control and Prevention (2020) Coronavirus disease 2019 (COVID-19): situation summary. https://bit. 1y/39WdBQX. Accessed 25 March 2020

3. Satou GM, Rheuban K, Alverson D et al (2017) Telemedicine in pediatric cardiology: a scientific statement from the American Heart Association. Circulation 135:e648-e678. https://doi. org/10.1161/CIR.0000000000000478

4. Sharma S, Parness IA, Kamenir SA et al (2003) Screening fetal echocardiography by telemedicine: efficacy and community acceptance. J Am Soc Echocardiogr Off Publ Am Soc Echocardiogr 16:202-208. https://doi.org/10.1067/mje.2003.46

5. Randolph GR, Hagler DJ, Khandheria BK et al (1999) Remote telemedical interpretation of neonatal echocardiograms: impact on clinical management in a primary care setting. J Am Coll Cardiol 34:241-245. https://doi.org/10.1016/s0735-1097(99)00182-5

6. Fisher JB, Alboliras ET, Berdusis K, Webb CL (1996) Rapid identification of congenital heart disease by transmission of echocardiograms. Am Heart J 131:1225-1227. https://doi.org/10.1016/ s0002-8703(96)90103-9

7. Mulholland HC, Casey F, Brown D et al (1999) Application of a low cost telemedicine link to the diagnosis of neonatal congenital heart defects by remote consultation. Heart (Br Card Soc) 82:217-221. https://doi.org/10.1136/hrt.82.2.217

8. Sable C (2001) Telecardiology: potential impact on acute care. Crit Care Med 29:N159-N165. https://doi.org/10.1097/00003246200108001-00004

9. Dehghani P, Atallah J, Rebeyka I et al (2013) Management of adults with congenital heart disease using videoconferencing across Western Canada: a 3-year experience. Can J Cardiol 29:873-878. https://doi.org/10.1016/j.cjca.2012.06.016

10. Sable CA, Cummings SD, Pearson GD et al (2002) Impact of telemedicine on the practice of pediatric cardiology in community hospitals. Pediatrics 109:E3. https://doi.org/10.1542/ peds.109.1.e3

11. Maia MR, Castela E, Pires A, Lapao LV (2019) How to develop a sustainable telemedicine service? A Pediatric Telecardiology
Service 20 years on-an exploratory study. BMC Health Serv Res 19:681. https://doi.org/10.1186/s12913-019-4511-5

12. Geoffroy O, Acar P, Caillet D et al (2008) Videoconference pediatric and congenital cardiology consultations: a new application in telemedicine. Arch Cardiovasc Dis 101:89-93. https ://doi.org/10.1016/s1875-2136(08)70264-x

13. de Araújo JSS, Dias Filho AV, Silva Gomes RG et al (2015) Impact of a virtual clinic in a paediatric cardiology network on northeast Brazil. Int J Telemed Appl 2015:504015. https://doi. org/10.1155/2015/504015

14. Singh S, Bansal M, Maheshwari P et al (2013) American Society of Echocardiography: Remote Echocardiography with WebBased Assessments for Referrals at a Distance (ASE-REWARD) Study. J Am Soc Echocardiogr Off Publ Am Soc Echocardiogr 26:221-233. https://doi.org/10.1016/j.echo.2012.12.012

15. Hsieh J-C, Li A-H, Yang C-C (2013) Mobile, cloud, and big data computing: contributions, challenges, and new directions in telecardiology. Int J Environ Res Public Health 10:6131-6153. https://doi.org/10.3390/ijerph10116131

16. Miyashita T, Takizawa M, Nakai K et al (2003) Telemedicine of the heart: real-time telescreening of echocardiography using satellite telecommunication. Circ J Off J Jpn Circ Soc 67:562-564. https://doi.org/10.1253/circj.67.562

17. Cavero E, Alesanco A, Castro L et al (2013) SPIHT-based echocardiogram compression: clinical evaluation and recommendations of use. IEEE J Biomed Health Inform 17:103-112. https://doi.org/10.1109/TITB.2012.2227336

18. Choi BG, Mukherjee M, Dala P et al (2011) Interpretation of remotely downloaded pocket-size cardiac ultrasound images on a web-enabled smartphone: validation against workstation evaluation. J Am Soc Echocardiogr Off Publ Am Soc Echocardiogr 24:1325-1330. https://doi.org/10.1016/j.echo.2011.08.007

19. Finley JP, Warren AE, Sharratt GP, Amit M (2006) Assessing children's heart sounds at a distance with digital recordings. Pediatrics 118:2322-2325. https://doi.org/10.1542/ peds.2006-1557

20. Dahl LB, Hasvold P, Arild E, Hasvold T (2002) Heart murmurs recorded by a sensor based electronic stethoscope and e-mailed for remote assessment. Arch Dis Child 87:297-301. https://doi. org/10.1136/adc.87.4.297

21. Mahnke CB, Mulreany MP, Inafuku J et al (2008) Utility of storeand-forward pediatric telecardiology evaluation in distinguishing normal from pathologic pediatric heart sounds. Clin Pediatr 47:919-925. https://doi.org/10.1177/0009922808320596

22. Malloy LE, Gingerich J, Olson MD, Atkins DL (2014) Remote monitoring of cardiovascular implantable devices in the pediatric population improves detection of adverse events. Pediatr Cardiol 35:301-306. https://doi.org/10.1007/s00246-013-0774-5

23. Schickendantz S, Pillekamp F, Emmel M et al (2006) Wireless Holter transmission in suspected dysrhythmias. J Electrocardiol 39:S54-S56. https://doi.org/10.1016/j.jelectrocard.2006.05.022

24. Dechert BE, Serwer GA, Bradley DJ et al (2015) Cardiac implantable electronic device remote monitoring surveillance in pediatric and congenital heart disease: utility relative to frequency. Heart Rhythm 12:117-122. https://doi.org/10.1016/j.hrthm.2014.10.009

25. Rothman SA, Laughlin JC, Seltzer J et al (2007) The diagnosis of cardiac arrhythmias: a prospective multi-center randomized study comparing mobile cardiac outpatient telemetry versus standard loop event monitoring. J Cardiovasc Electrophysiol 18:241-247. https://doi.org/10.1111/j.1540-8167.2006.00729.x

26. Dubner S, Auricchio A, Steinberg JS et al (2012) ISHNE/EHRA expert consensus on remote monitoring of cardiovascular implantable electronic devices (CIEDs). Eur Pacing Arrhythm Card Electrophysiol J Work Groups Card Pacing Arrhythm Card Cell Electrophysiol Eur Soc Cardiol 14:278-293. https://doi.org/10.1093/ europace/eur303 
27. Burke BLJ, Hall RW (2015) Telemedicine: pediatric applications. Pediatrics 136:e293-e308. https://doi.org/10.1542/ peds.2015-1517

28. Marcin JP, Trujano J, Sadorra C, Dharmar M (2009) Telemedicine in rural pediatric care: the fundamentals. Pediatr Ann 38:224-226. https://doi.org/10.3928/00904481-20090401-10

29. Krupinski EA, Bernard J (2014) Standards and guidelines in telemedicine and telehealth. Healthcare (Basel Switz) 2:74-93. https ://doi.org/10.3390/healthcare2010074

30. Meyer BC, Clarke CA, Troke TM, Friedman LS (2012) Essential telemedicine elements (telements) for connecting the academic health center and remote community providers to enhance patient care. Acad Med J Assoc Am Med Coll 87:1032-1040. https://doi. org/10.1097/ACM.0b013e31825cdd3a

31. Hall-Barrow J, Hall RW, Burke BLJ (2009) Telemedicine and neonatal regionalization of care-ensuring that the right baby gets to the right nursery. Pediatr Ann 38:557-561. https://doi. org/10.3928/00904481-20090918-02

32. Kim EW, Teague-Ross TJ, Greenfield WW et al (2013) Telemedicine collaboration improves perinatal regionalization and lowers statewide infant mortality. J Perinatol Off J Calif Perinat Assoc 33:725-730. https://doi.org/10.1038/jp.2013.37

33. Sekar P, Vilvanathan V (2007) Telecardiology: effective means of delivering cardiac care to rural children. Asian Cardiovasc Thorac Ann 15:320-323. https://doi.org/10.1177/021849230701500411

34. Webb CL, Waugh CL, Grigsby J et al (2013) Impact of telemedicine on hospital transport, length of stay, and medical outcomes in infants with suspected heart disease: a multicenter study. J Am Soc Echocardiogr Off Publ Am Soc Echocardiogr 26:1090-1098. https://doi.org/10.1016/j.echo.2013.05.018

35. Marcin JP, Nesbitt TS, Kallas HJ et al (2004) Use of telemedicine to provide pediatric critical care inpatient consultations to underserved rural Northern California. J Pediatr 144:375-380. https:// doi.org/10.1016/j.jpeds.2003.12.017

36. Backman W, Bendel D, Rakhit R (2010) The telecardiology revolution: improving the management of cardiac disease in primary care. J R Soc Med 103:442-446. https://doi.org/10.1258/ jrsm.2010.100301

37. Armfield NR, Donovan T, Bensink ME, Smith AC (2012) The costs and potential savings of telemedicine for acute care neonatal consultation: preliminary findings. J Telemed Telecare 18:429433. https://doi.org/10.1258/jtt.2012.gth101

38. Sayani S, Muzammil M, Saleh K et al (2019) Addressing cost and time barriers in chronic disease management through telemedicine: an exploratory research in select low- and middle-income countries. Ther Adv Chronic Dis 10:2040622319891587. https:// doi.org/10.1177/2040622319891587

39. Smith CE, Fontana-Chow K, Boateng BA et al (2009) Tele-education: linking educators with learners via distance technology. Pediatr Ann 38:550-556. https://doi.org/10.3928/0090448120090918-10

40. González-Espada WJ, Hall-Barrow J, Hall RW et al (2009) Achieving success connecting academic and practicing clinicians through telemedicine. Pediatrics 123:e476-e483. https:// doi.org/10.1542/peds.2008-2193

41. Jain A, Agarwal R, Chawla D et al (2010) Tele-education vs classroom training of neonatal resuscitation: a randomized trial. J Perinatol Off J Calif Perinat Assoc 30:773-779. https://doi. org/10.1038/jp.2010.42

42. Jauhar S (2004) House calls. N Engl J Med 351:2149-2151. https ://doi.org/10.1056/NEJMp048109

43. Telehealth and COVID-19 (2020). AAP.org. https://youtu.be/ Cj0s3alpZKI. Accessed 23 March 2020

44. Thibodeau JT, Drazner MH (2018) The role of the clinical examination in patients with heart failure. JACC Heart Fail 6:543-551. https://doi.org/10.1016/j.jchf.2018.04.005
45. Desai S, Williams ML, Smith AC (2013) Teleconsultation from a secondary hospital for paediatric emergencies occurring at rural hospitals in Queensland. J Telemed Telecare 19:405-410. https://doi.org/10.1177/1357633X13506528

46. Weatherburn G, Dowie R, Mistry H, Young T (2006) An assessment of parental satisfaction with mode of delivery of specialist advice for paediatric cardiology: face-to-face versus videoconference. J Telemed Telecare 12(Suppl 1):57-59. https://doi. org/10.1258/135763306777978560

47. McConnochie KM, Wood NE, Herendeen NE et al (2010) Telemedicine in urban and suburban childcare and elementary schools lightens family burdens. Telemed J e-Health Off J Am Telemed Assoc 16:533-542. https://doi.org/10.1089/ tmj.2009.0138

48. Grealish A, Hunter A, Glaze R, Potter L (2005) Telemedicine in a child and adolescent mental health service: participants' acceptance and utilization. J Telemed Telecare 11(Suppl 1):53-55. https ://doi.org/10.1258/1357633054461921

49. Davis AM, James RL, Boles RE et al (2011) The use of TeleMedicine in the treatment of paediatric obesity: feasibility and acceptability. Matern Child Nutr 7:71-79. https://doi.org/10.111 1/j.1740-8709.2010.00248.x

50. Jury SC, Walker AM, Kornberg AJ (2013) The introduction of web-based video-consultation in a paediatric acute care setting. J Telemed Telecare 19:383-387. https://doi.org/10.1177/13576 33X13506530

51. Dudas RA, Pumilia JN, Crocetti M (2013) Pediatric caregiver attitudes and technologic readiness toward electronic follow-up communication in an urban community emergency department. Telemed J e-Health Off J Am Telemed Assoc 19:493-496. https ://doi.org/10.1089/tmj.2012.0166

52. Hopper B, Buckman M, Edwards M (2011) Evaluation of satisfaction of parents with the use of videoconferencing for a pediatric genetic consultation. Twin Res Hum Genet Off J Int Soc Twin Stud 14:343-346. https://doi.org/10.1375/twin.14.4.343

53. Lee J-Y, Du YE, Coki O et al (2010) Parental perceptions toward digital imaging and telemedicine for retinopathy of prematurity management. Graefe's Arch Clin Exp Ophthalmol 248:141-147. https://doi.org/10.1007/s00417-009-1191-6

54. Harahsheh AS, Hom LA, Clauss SB et al (2016) The impact of a designated cardiology team involving telemedicine home monitoring on the care of children with single-ventricle physiology after Norwood palliation. Pediatr Cardiol 37:899-912. https://doi. org/10.1007/s00246-016-1366-y

55. Castellanos DA, Herrington C, Adler S et al (2016) Home monitoring program reduces mortality in high-risk sociodemographic single-ventricle patients. Pediatr Cardiol 37:1575-1580. https:// doi.org/10.1007/s00246-016-1472-x

56. Ugonabo N, Hirsch-Romano JC, Uzark K (2015) The role of home monitoring in interstage management of infants following the Norwood procedure. World J Pediatr Congenit Heart Surg 6:266-273. https://doi.org/10.1177/2150135114563771

57. Polisena J, Tran K, Cimon K et al (2010) Home telemonitoring for congestive heart failure: a systematic review and metaanalysis. J Telemed Telecare 16:68-76. https://doi.org/10.1258/ jtt.2009.090406

58. Pekmezaris R, Tortez L, Williams M et al (2018) Home telemonitoring in heart failure: a systematic review and meta-analysis. Health Aff (Proj Hope) 37:1983-1989. https://doi.org/10.1377/ hlthaff.2018.05087

59. Bernocchi P, Scalvini S, Bertacchini F et al (2014) Home based telemedicine intervention for patients with uncontrolled hypertension-a real life non-randomized study. BMC Med Inform Decis Mak 14:52. https://doi.org/10.1186/1472-6947-14-52

60. Rogers MAM, Buchan DA, Small D et al (2002) Telemedicine improves diagnosis of essential hypertension compared 
with usual care. J Telemed Telecare 8:344-349. https://doi. org/10.1258/135763302320939239

61. Kaur R, Kajal KS, Kaur A, Singh P (2015) Telephonic consultation and follow-up in diabetics: impact on metabolic profile, quality of life, and patient compliance. N Am J Med Sci 7:199-207. https://doi.org/10.4103/1947-2714.157483

62. Kirkpatrick JN, Mitchell C, Taub C et al (2020) ASE statement on protection of patients and echocardiography service providers during the 2019 novel coronavirus outbreak. J Am Coll Cardiol. https://doi.org/10.1016/j.jacc.2020.04.002

63. Moller JH, Allen HD, Clark EB et al (1993) Report of the task force on children and youth. Circulation (Am Heart Assoc) 88:2479-2486. https://doi.org/10.1161/01.cir.88.5.2479

64. Estrada CA, Rosman HS, Prasad NK et al (1995) Role of telemetry monitoring in the non-intensive care unit. Am J Cardiol 76:960-965. https://doi.org/10.1016/s0002-9149(99)80270-7

65. Mabo P, Victor F, Bazin P et al (2012) A randomized trial of longterm remote monitoring of pacemaker recipients (the COMPAS trial). Eur Heart J 33:1105-1111. https://doi.org/10.1093/eurhe artj/ehr419

66. Movsowitz C, Mittal S (2011) Remote patient management using implantable devices. J Interv Card Electrophysiol Int J Arrhythm Pacing 31:81-90. https://doi.org/10.1007/s10840-011-9548-2

67. Raatikainen MJP, Uusimaa P, van Ginneken MME et al (2008) Remote monitoring of implantable cardioverter defibrillator patients: a safe, time-saving, and cost-effective means for followup. Eur Pacing Arrhythm Card Electrophysiol J Work Groups Card Pacing Arrhythm Card Cell Electrophysiol Eur Soc Cardiol 10:1145-1151. https://doi.org/10.1093/europace/eun203

68. Barker PC, Lewin M, Donofrio MT et al (2020) Specific considerations for pediatric, fetal, and congenital heart disease patients and echocardiography service providers during the 2019 novel coronavirus outbreak: Council on Pediatric and Congenital Heart Disease Supplement to the Statement of the American Society of Echocardiography. asecho.org. https://www.asecho.org/covid-19resources/pchd-statement-on-covid-19/. Accessed 5 April 2020

69. Ghanayem NS, Hoffman GM, Mussatto KA et al (2003) Home surveillance program prevents interstage mortality after the Norwood procedure. J Thorac Cardiovasc Surg 126:1367-1377. https ://doi.org/10.1016/s0022-5223(03)00071-0

70. Bingler M, Erickson LA, Reid KJ et al (2018) Interstage outcomes in infants with single ventricle heart disease comparing home monitoring technology to three-ring binder documentation: a randomized crossover study. World J Pediatr Congenit Heart Surg 9:305-314. https://doi.org/10.1177/2150135118762401

71. Shirali G, Erickson L, Apperson J et al (2016) Harnessing teams and technology to improve outcomes in infants with single ventricle. Circ Cardiovasc Qual Outcomes 9:303-311. https://doi. org/10.1161/CIRCOUTCOMES.115.002452

72. Morales DLS, Rossano JW, VanderPluym C et al (2019) Third Annual Pediatric Interagency Registry for Mechanical Circulatory Support (Pedimacs) Report: Preimplant Characteristics and Outcomes. Ann Thorac Surg 107:993-1004. https://doi. org/10.1016/j.athoracsur.2019.01.038

73. Critical updates on COVID-19 (2020). AAP.org. https://services. aap.org/en/pages/2019-novel-coronavirus-covid-19-infections/

74. Ross RD, Brook M, Koenig P et al (2015) 2015 SPCTPD/ACC/ AAP/AHA Training Guidelines for Pediatric Cardiology Fellowship Programs (Revision of the 2005 Training Guidelines for Pediatric Cardiology Fellowship Programs). J Am Coll Cardiol 66:670-671. https://doi.org/10.1016/j.jacc.2015.03.004

75. Nasca T (2020) ACGME response to the coronavirus (COVID19). ACGME.org. https://www.acgme.org/Newsroom/NewsroomDetails/ArticleID/10111/ACGME-Response-to-the-Coronaviru s-COVID-19

76. Telehealth care and after hours care (2020). AAP.org. https:// www.aap.org/en-us/professional-resources/practice-transforma tion/managing-patients/telehealth-care/Pages/default.aspx

77. COVID 19 coronavirus disease 2019 what you need to know about telehealth coding best practices and more (2020). ACC. org. https://www.acc.org/latest-in-cardiology/features/accs-coron avirus-disease-2019-covid-19-hub/what-you-need-to-know-about -telehealth-coding-best-practices-and-more-covid-19-coronaviru s-disease-2019

78. Wosik J (2019) Telehealth primer for cardiology fellows. ACC. org. https://www.acc.org/membership/sections-and-councils/fello ws-in-training-section/section-updates/2019/08/20/14/42/teleh ealth-primer-for-cardiology-fellows

79. Wosik J (2019) Best practices for providing telehealth services. ACC.org. https://www.acc.org/membership/sections-and-counc ils/fellows-in-training-section/section-updates/2019/09/17/14/42/ best-practices-for-providing-telehealth-services

80. Dodeja A (2020) Telemedicine and CV training during the COVID-19 pandemic. ACC.org. https://www.acc.org/membership /sections-and-councils/fellows-in-training-section/section-updat es/2020/04/13/12/42/telemedicine-and-cv-training-during-thecovid-19-pandemic

81. Almarzooq Z, Lopes M, Kochar A (2020) Virtual learning during the COVID-19 pandemic: a disruptive technology in graduate medical education. J Am Coll Cardiol. https://doi.org/10.1016/j. jacc.2020.04.015

82. DeFilippis EM, Stefanescu Schmidt AC, Reza N (2020) Adapting the educational environment for cardiovascular fellows-in-training during the COVID-19 pandemic. J Am Coll Cardiol. https://doi. org/10.1016/j.jacc.2020.04.013

83. Heart University (2020). https://www.heartuniversity.org/. Accessed 11 May 2020

Publisher's Note Springer Nature remains neutral with regard to jurisdictional claims in published maps and institutional affiliations. 